\title{
Infill development as an approach for promoting compactness of urban form
}

\author{
S. S. Aly \& Y. A. Attwa \\ Department of Architecture and Environmental Design, \\ Arab Academy for Science and Technology and \\ Maritime Transport, Egypt
}

\begin{abstract}
In the last few decades, urban decay has increased within the city urban fabric; due to the deterioration of the inner city and increase in population. High income citizens abandoned their houses demanding a better quality of life outside the city fabric, leading the old city to be occupied by poorer households or left vacant. Urban decay is linked to suburban sprawl as the economic life is pulled out of the city, instead of a previously developed urban site within the old city fabric. Infill development is the new development of vacant, abandoned, passed over, or underutilized land within built-up areas of existing communities, where infrastructure is already in place. It is a solution to filling gaps in existing communities and playing a critical role in achieving community revitalization, land conservation and alternatives to sprawl development. Taking advantage of existing infrastructure, increasing walkability by contributing safe and attractive pedestrian environment, creating new opportunities for mixed use that recapture the "sense of place" that is largely missing in development projects. Infill development is a solution to enhancing the character, viability and function of the old city. The aim of this research is to articulate the potential and limits of infill development. It focuses on factors that influence decisions to introduce infill development as an approach to smart growth and a solution to urban decay. This is achieved by analyzing international and local examples of infill development to identify the different land use of vacant land in different urban contexts. An analytical comparison is carried on the examples, to achieve broad recommendations for infill development in different urban contexts.

Keywords: infill development, urban sprawl, revitalization, smart growth.
\end{abstract}




\section{Introduction}

Communities are extending outside the city fabric and beyond the city's edge. The suburbs became attractive to middle and upper class residents. There is an increasing emphasis on developing vacant lands within developed areas and maximizing use of existing public facilities. Urban planning have cured vacant land and urban decay by infill development as a solution to sprawl that will both increase density and revitalize depressed neighborhoods (Faris [1] and Robinson and Cole [2]). Infill development has the potential to have dramatic effects on urban density and urban form. Successful infill development focuses on the existing community fabric, filling gaps in the neighborhood. It is characterized by a healthy mix of uses to support transit and wider variety of services and amenities providing vitality to the communities. Despite the many advantages associated with infill development, there are a number of challenges and barriers prohibit its development. Infill faces political, economical and logistical barriers. The comprehensive infill development is discussed in this paper addressing development impacts, with a focus on integrating new development with existing patterns. It is indented to assist in making more informed decisions when submitting or reviewing site plan or re-zoning vacant lots within the city urban form.

\subsection{Problem definition}

Due to high population density, communities are extending in patterns outside the city defined edges. Increased infrastructure costs, lengthy commutes and strained public amenities, loss of open space and community health are typically connected with such patterns, destroying existing street systems and distributing the morphology of the open space. Developers bypassing vacant land area for less expensive land beyond the city edges, rather than filling the inner city gaps. According to Downs [3], buildings become neglected when "structures have been converted to higher-density uses than those for which they were designed". Also, as the zoning within that location still remains, the surrounding urban fabric and zoning are very slow to change in response to new demand. Higher income residents demanding a higher quality of life, however social problems and crime arises within the city which has been related to lack of diversity and attributed to sprawl. Brownfield is another cause for city portions losing their viability, obsolescence and its relationship to renovation cost in non-residential buildings. When all the pervious factors occur, they constitute a fracture in the wholeness of the urban form. The great number of sites in this highly damaged condition and their negative impact on the surroundings make their development a matter of great importance (Trancik [10]).

\subsection{Urban sprawl and smart growth}

Sprawl has been linked to loss of open space, and the exponential increase in new infrastructure costs. Smart growth creates a supportive environment for redirecting a share of regional growth to inner cities. Infill development is a key 
component of smart growth. The formulation of the US Green Building Council's LEED ${ }^{\circledR}$ building guidelines has created a national standard for developing sustainable communities by encouraging strategies for sustainable site development, including infill development. The new urbanism movement also supported infill development as they stated in the charter of new urbanism that developement pattern should not blur or eradicate the edges of the metropolis (CNU [4]).

\subsection{Identifying infill development}

Infill development is the new development of vacant, abandoned, passed over, or underutilized land within built-up areas of existing communities, where infrastructure is already in place. The demolition of existing structures and building new structures or the substantial renovation of existing structures, often changing form and function. Infill sites could be divided into vacant lots which often become dumping grounds for waste, posing health and safety hazards, abandoned properties which requires maintenance and demolition costs or brownfields, which are usually lands where old industries, other businesses and warehouses were held.

\section{Benefits of infill development}

- Enhances the compactness of urban form, as it promotes relatively high density with mixed land uses. It enhance the character and respects historic preservation.

- Increase the efficiency of public transport and urban layout, encouraging walkability, capitalizing on existing infrastructure and minimizes the need for costly new ones thus, providing opportunities for social interaction as well as feeling of safety and belonging.

- Maintain and restores spatial continuity to streetscapes enhancing viability and function of existing communities.

- Introduces compatible uses that complement existing community attributes and needs by increasing the supply of housing types and improving the quality of building stock and revival of city centres.

- Utilizing public facilities to promote the economic health of the city, injecting new life into communities.

- Conserves environmental resources, economic investiment, and social fabric, while reclaiming marginal and abondoned areas.

\section{Barriers to infill development}

There are different barriers that affect infill development, these barriers include: physical barriers, social barriers, regulatory barriers, economic barriers, infrastructure barriers and the scale of development (Faris [1]). 


\section{Design principles of a successful infill development}

Infill projects should enhance the design and function of the existing community. Infill encompasses many different forms and interpretations. Appearance and function of infill should respect the following common principles:

- Sociability

- Diversity: provide a broad range of housing types and price levels to bring people of diverse ages, races, and incomes into daily interactionstrengthening the personal and civic bonds essential to an authentic community (CNU [4]).

- $\quad$ Sense of place: the degree to which settlement can be achieved and mentally differentiated and structured in time and space by residents, the degree of which their mental structure connects with their values and concepts (Lynch [5]).

- Public participation: infill takes place in established communities, input from area residents should be sought, preferably during the infill planning process, and before specific projects are proposed. Gaining the cooperation and trust of the community is critically important

- Political support and commitment: strong political leadership is a necessary component of successful infill development (Faris [1]).

- Density: infill could be developed at a sprawl-like density; however, because of the characteristically high costs of infill land, this type of development will generally occur at higher densities that further smart growth (Ewing [6]).

- Comfort and image aspects

- Compatibility: is a largely subjective measure of how well new construction or substantial rehabilitation fits into the existing community structure. Pattern, alignment, size, and shape are the essential elements of compatibility. These elements define the basic relationships between new and old buildings without referencing a specific style of architecture.

- The comprehensive plan: the comprehensive plan should establish a policy basis, goals and objectives for the infill strategy and identify desired characteristics for infill development opportunities.

- Zoning regulations: zoning regulations should support infill and include a clear articulation of intent that reinforces the provisions in the comprehensive plan. There are many zoning options available, including changing an existing zone, or creating a new zone, an overlay zone, or a floating zone. The use of administrative waivers provides a more 'user-friendly' regulatory environment that increases speed and certainty such as: Height, Setback, Bulk, Parking, Area.

- Design codes: the economic health and harmonious evolution of neighborhoods can be improved through graphic urban design codes that serve as predictable guides for change (CNU [4]).

- Identity: while the continuation of existing community character may be a priority in established neighborhood areas, contribution to a desired 
future character may be more important than compatibility in areas where change is expected and desired, such as in mixed-use centers.

- Adaptability: buildings and developments should be designed to offer variety and flexibility, the need to create developments and buildings with a clear form and function.

- Public realm: maximize usable open space when possible. Smart growth emphasizes the public space (e.g., streetscapes and pedestrian environment), while sprawl emphasizes the private realm (Ewing [6]).

- Secure environment: orient windows and entrances to the public realm to provide opportunities for "eyes on the street" and community interaction (CNU [4]).

- Uses and activities aspects

- Mixed use: promote the creation of mixed use neighborhoods that support the functions of daily life and enhance sustainability (CNU [4]).

- Land property value: infill development increases the economic value of the surrounding land, attracting investors and residents to the area.

- $\quad$ Access and linkage aspects

- Parking: parking regulations should be adjusted to accommodate infill development. Parking requirements in zoning ordinances can hinder infill projects.

- Integration: development is to promote the integration of the infill development into the city through planning, urban design, community involvement, and the provision of public amenities.

- Walkability: it offers increased mobility for people, it minimizes traffic congestion. Higher density community allows easier carpooling, maximising use of public transportation and increasing walkability.

- Connectivity: infill that is not well connected to surrounding roads, sidewalks, is poorly planned (Ewing [6]).

\section{Analytical examples}

\subsection{Southeast False Creek, Vancouver Canada.}

False Creek was used by residents for fishing; its shoreline was developed by industry and businesses that filled in to create more industrial use. For the last few decades, these buildings have been abandoned and occupied by sawmills, shipbuilders, metalwork, etc. (City of Vancouver [7]).

\subsubsection{Features of False Creek neighborhood}

Infill scale: large scale - waterfront neighborhood development, site area: 67 hectares, population: 10,570 in 2006, density: 390 dwellings/hectare, built form: medium and high-rise towers ranging from 6-17 storey, open space: 1.0 hectare per 1000 residents, $25 \%$ of the total site area. 


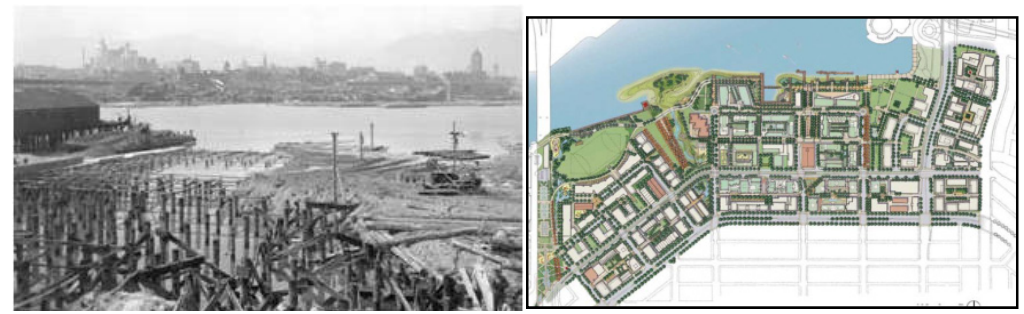

Figure 1: Industrial site of False Creek before and after development.

\subsubsection{Project objectives}

- Transfer the industrial/brownfield site into a sustainable, mixed use neighborhood.

- Establish a foundation of sustainability principles, and environmental, social, and economic strategies to enable the development as a complete community, and to serve as a learning experience or application of such principles on a broader scale.

- $\quad$ Provide a framework for the creation of policies, zoning, public facilities, subdivision plans, design guidelines and forms of development (City of Vancouver [7]).

\subsubsection{Design evaluation according to principles of successful infill development}

Table 1 shows the design criteria.

Table 1: $\quad$ Design criteria (source: City of Vancouver [7]).

- Promoting a variety of houses, social and physical infrastructure, enhancing accessibility and connecting it to the water edge with a variety of activities.

- Develop a community that can grow and adapt itself to sustainability principles.

- Street network is maintained to serve residents to achieve walkability and public ream

- Creating a framework for economically viable community employment.

- Provides integration of land uses within a compact urban form

- Design of row houses, legible development, building heights stepping down to the water front.

- Re-zoning regulations adopted by Councils. Change of land use from industrial to mixed use conserving and managing the ecosystem health

- Encourage awareness among residents about sustainability and its role in creating fully developed neighborhoods.
Diversity, mixed use, connectivity, adaptability, public realm, integration, sustainability, liveability and walkability.

Economic aspects and land property value.

Compatibility and integration

Design codes, building regulations mixed use and zoning regulations. 


\subsection{Al-Azhar Park Cairo, Egypt}

The old Al-Azhar Park site has been a debris dump for over 500 years. The area had witnessed a marked decline and a thriving drug trade in the 1980s, left it with a reputation for being crime-ridden and unsafe. The Al-Azhar Park has created welcome opportunities for parallel rehabilitation efforts in Darb AlAhmar, the impoverished and densely built-up district that borders the Park.

\subsubsection{Features of Al-Azhar Park}

Infill type: vacant land/brownfield, infill scale: large scale - open space, site area: 30 hectares, population: 90,000 residents in Darb Al-Ahmar quarter.

It is located within the historic and touristic area of the old downtown in Cairo. The measures successfully carried out by the Agakhan Trust for cultures to restore and renew the Darb Al-Ahmar quarter, huge portions of the old Islamic quarter are overwhelmed by the decay of building fabric, very high population and occupancy density, a largely predominant lower class and informal commercial structures (Bandarin and van Oers [8]).
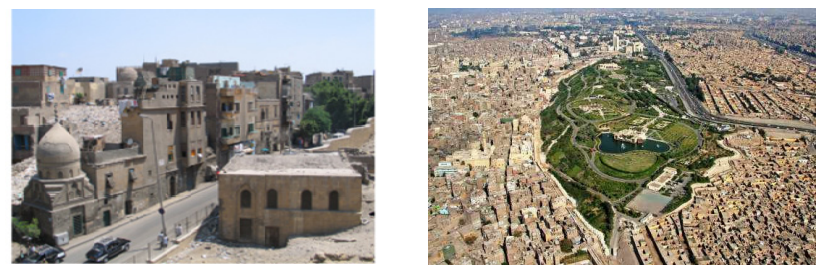

Figure 2: $\quad$ Al-Azhar Park infill before and after the development.

\subsubsection{Project objectives}

- $\quad$ Transfer the brownfield land into an open park providing a green lung for the highly compact historical area of Darb Al-Ahmar.

- Provides an ideal opportunity for renewed investment while preserve the area's urban qualities, to regenerate its economy and improve the area's physical assets through greater public and private investment.

- Comprehensive urban development to reverse the present decay, raise housing standards and introduce new commercial uses and economic activities on the blighted streets.

- $\quad$ Public and donor funding to improve the infrastructure and revitalize dormant assets, in particular its outstanding monuments.

\subsubsection{Design evaluation according to principles of successful infill development}

Table 2 shows the design criteria. 
Table 2: $\quad$ Design criteria (source Bandarin and van Oers [8]).

- Vacant lots on Burg Al-Zafar can be used to meet the current housing shortage with new residential developments that are attractive to residents.

- Introducing new multi-functional commercial structure.

- Keeping the identity of the old Islamic architecture that was built with the area of Darb Al-Ahmar and providing the park with the same spirit in a modern approach.

- Rejuvenating historic landmarks through adaptive reuse.

- Encourage awareness among residents. Residents shared and employed in the development and renovation project of Darb Al-Ahmar and the park.

- Social and educational programs introduced.

- Preserving the social fabric by providing residents with security of tenure.

- Primary infrastructure serving the district, with neighborhood accessibility from the city's network of streets and the integration of a walkable pedestrian network connecting the neighborhood and its public spaces with the park.

\subsection{Solidere downtown, Beirut, Lebanon}

The medieval city is largely lost because of the substantial urbanist deformations of the old town during the Ottoman period and the French Mandate and the demolitions during the war in the seventies and eighties and of the latest comprehensive renewal of the central district area. The Beirut city center is located at the heart of Lebanon's capital.

\subsubsection{Features of Solidere, Beirut downtown}

Infill type: vacant lands within the city center, infill scale: large scale downtown development, site area: 191 hectares, population: 40,000 residents, built form: medium scale buildings, from 5-6 storey, open space: 39 hectares.

\subsubsection{Project objectives}

- $\quad$ Transfer the abandoned, damaged buildings into high density mixed used development.

- Provide a functional and an attractive environment, using quality infrastructure, buildings and property management.

- $\quad$ Restoring life to this vital part of the country, traditionally a meeting place and the focus of economic and cultural activity.

- Delivering the tangible benefits of comprehensive planning, Beirut's downtown has re-emerged as a prime, active district, at the same time historic core, mixed use and social arena. 

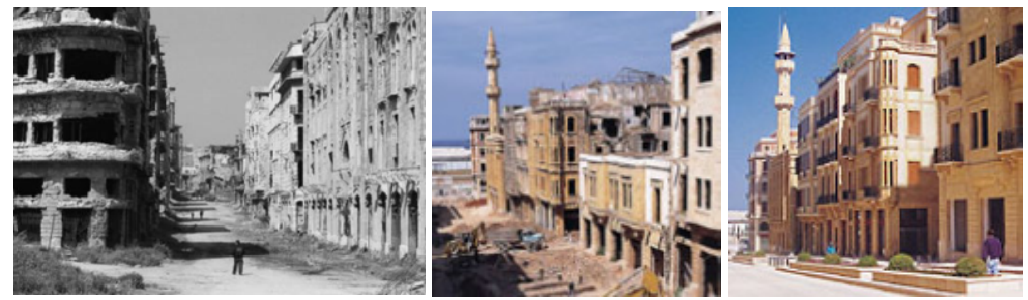

Figure 3: Infill development carried out in Solidere downtown (source: Solidere [9]).

\subsubsection{Design evaluation according to principles of successful infill development}

Table 3 shows the design criteria.

Table 3: $\quad$ Design criteria (source: Solidere [9]).

- Providing a variety of housing types, new residential quarters emerging in the center.

- A broad mix of land uses ranging from business and institutional to residential, cultural and recreational facilities.

- Mixed densities and commercial opportunities for the creation of an inclusive urban environment.

- Quality built form contributes to urban design of the old city of Beirut.

Preserving features of townscape, restoring the old downtown.

- The Solidere private company and the government both invested in the downtown infill project, allowing further local and international investments to take place.

- Public parking facilities which has a capacity to withstand the amount of residents of the downtown area and the outside daily visitors.

- Reconnecting the urban environment to the water's edge, creating a high quality public realm that promotes integration of a wide variety of outdoor recreation activities.
Diversity, density, compactness, compatibility, land use, mixed use and sustainability.

Sense of place, historic preservation and identity

Economic aspects, land property value.

Infrastructure, parking, accessibility, walkability, integration, vitality, connectivity and public realm. 


\section{Comparative analysis}

Table 4 shows the comparative analysis between the previously discussed examples.

Table 4: $\quad$ Comparative analysis of examples.

\begin{tabular}{|c|c|c|c|}
\hline Criteria & $\begin{array}{c}\text { False } \\
\text { Creek, } \\
\text { Vancouver }\end{array}$ & $\begin{array}{c}\text { Al- Azhar } \\
\text { park, Cairo. }\end{array}$ & $\begin{array}{l}\text { Solidaire, } \\
\text { Beirut. }\end{array}$ \\
\hline Type of infill development & City edge & Open space & Downtown \\
\hline \multicolumn{4}{|l|}{ Sociability } \\
\hline Diversity & - & - & 0 \\
\hline Sense of place & - & - & - \\
\hline Public participation & 0 & O & 0 \\
\hline Political support and commitment & - & - & - \\
\hline Economic aspects & - & 0 & - \\
\hline Education & - & O & - \\
\hline Density & 0 & - & 0 \\
\hline \multicolumn{4}{|l|}{ Comfort and image } \\
\hline Compatibility & - & - & - \\
\hline Comprehensive plan & 0 & 0 & 0 \\
\hline Zoning Regulation & - & & - \\
\hline Design Codes & - & & 0 \\
\hline Preserve Identity & 0 & - & 0 \\
\hline Adaptability & - & - & - \\
\hline Public realm & - & - & - \\
\hline Secure Environment & - & - & - \\
\hline \multicolumn{4}{|l|}{ Uses and Activities } \\
\hline Vitality & - & - & $\mathbf{0}$ \\
\hline Public Amenities & - & - & - \\
\hline Mixed use & - & 0 & - \\
\hline Land property value & - & - & - \\
\hline Sustainable & - & 0 & 0 \\
\hline \multicolumn{4}{|l|}{ Access and Linkage } \\
\hline Parking & - & 0 & - \\
\hline Integration & - & 0 & - \\
\hline Walkability & - & - & - \\
\hline Connectivity & - & - & - \\
\hline Network of streets & - & 0 & - \\
\hline Renewal of infrastructures & 0 & 0 & 0 \\
\hline
\end{tabular}

Source: researcher (Strong •, Moderate $\bigcirc$ ).

By comparing the three examples, the paper came to the following findings. False Creek waterfront neighbourhood transferred the industrial abandoned site into one of the largest urban redevelopment projects in North America, and has been recognized for bringing residents into the downtown core and people closer to their place of work, which has greatly reduced their commuting times and need for a private vehicle, managed urban sprawl and density problems. Although a flexible approach is required to allow optimal use of parking space and a more sufficient social infrastructure is necessary to reflect the needs and 
income ranges of the community. Infill development at city edge requires an appropriate plan for the extension of infrastructure and a detailed study of its surrounding land uses. On the other hand, infill development carried in the AlAzhar Park "open space" allowed the revitalization of the whole surrounding context of Darb Al-Ahmar. Based on these studies, the area's land use map was found to be of very high dense residential neighborhood, lacking mixed use and low social interaction. It has survived the economic, environmental and social changes through focusing upon its culture background, urban transformation, establishing magnet projects within the area. The project was aspiring to educate the people living in the area, increasing their awareness about the historical neighborhood of Darb Al-Ahmar. Encouraging them to participate in the renovation project, promoting their sense of belonging to the area. However, with the introduction of this unique infill development in the city of Cairo, a problem was raised in which the infrastructure wasn't planned to handle the increased bearing capacity of the outsiders from the rest of the city. Finally, infill development carried at the downtown of the city of Beirut has considered some major urban development aspects such as, the existing and renewed infrastructure, the need to build a high standard streetscape and public spaces. It also considered the surrounding density of the existing context as it will attract residents and new investment into the area. Outside the historic core of the downtown a mechanism that relates adjacent green areas to successful land sales and rising land values. The restoration of old buildings with the preserving of the surrounding identity of historical context and adding new ones that contribute to the architectural design.

\section{Conclusion}

Infill development was carried out in different urban contexts (at the city edge, at the downtown and as an open space); a comparative analysis on the criteria of infill development was carried out on each example (shown in table 4). Infill development could be applied in vacant lands at the edge of the city where land use maps of surrounding context are considered, keeping the city's edge defined.

It could be applied to high density areas changing the land use into an open space while providing the surrounding context with central features in organizing the community, and connecting it with the adjacent areas. When carrying infill development in downtowns, there is an increased emphasis on using the existing infrastructure and providing a mixed use commercial center with the need of preserving its cultural and historical identity, creating liveable city centers.

Infill development promises to contribute to the solution of the problems associated with sprawling land use patterns. It can support increased transportation choices, a more efficient use of land and infrastructure, more varied and affordable housing types, savings for local government budgets, reduced pollution, improved economic health and better quality of life. 


\section{Recommendations}

- A successful infill development program will require more than a narrow focus. Instead, a cooperative partnership with the broader focus of competing the existing community fabric.

- Downtown should include relatively high-density mix of retail, office, services, and employment in downtown to serve a regional market area.

- Residential development should reinforce the traditional town center through a combination of restoration of historic buildings in the downtown area and compatible new infill development targeted to a broad range of income levels.

- Open spaces introduced as infill development project should consider the surrounding density, accessibility and existing infrastructure.

- Examine existing codes and searching for more flexible ways to shape development. A creative combination of strategies will best accomplish a comprehensive infill development.

- Concerns about safety, quality of education and quality of public and commercial services may need to be addressed, in addition to concerns about design, finance and political interference.

\section{References}

[1] Faris, J. Terrence, The Barriers to Using Infill Development to Achieve Smart Growth, Housing Policy Debate 12 (1): 1-30, 2001.

[2] Robinson and Cole LLP Best Practices to Encourage Infill Development. Association of prepared for the National Associaion of Realtors, 2002.

[3] Downs, Anthony. Neighborhoods and urban developement. Washington DC: The Brookings Institution, 1981.

[4] Charter of New Urbanism. Charter of New Urbanism. New York: McGraw, www.cnu.org, 2000.

[5] Lynch, Kevin. Good City Form. Massachusetts Institute of Technology, 1981.

[6] Ewing, Reid. "Best development practices.” Chicago Press. 1996. www.planning.org (accessed 12 20, 2012).

[7] Official Development Plan By-laws. “City Of Vancouver.” April 2007. http://vancouver.ca/green-vancouver.aspx (accessed January 20, 2013).

[8] Bandarin, Francesco and van Oers, Ron The historic urban landscape. UK: Wiley Blackwell, 2012.

[9] Solidere, 2010. [Online]. Available: http://www.solidere.com. [Accessed 122 2012].

[10] Trancik, R. Finding Lost Space -Theories of Urban Design, New York: Van Nostrand Reinhold, 1986. 